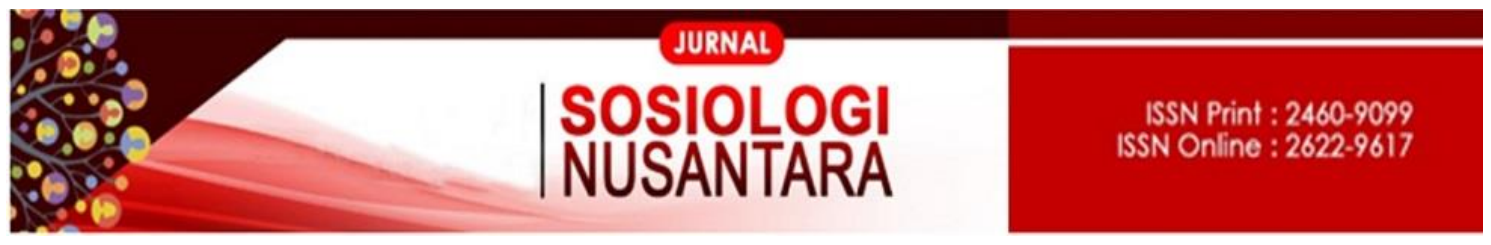

https://ejournal.unib.ac.id/index.php/jsn

DOI ://doi.org/10.33369/jsn.3.2.64-70

\title{
BURUKNYA GIZI IBU HAMIL PADA KELUARGA MISKIN \\ (Studi Kasus di Desa Sri Kuncoro Kecamatan Pondok Kelapa, Kabupaten Bengkulu Tengah)
}

\section{POOR NUTRITION OF PREGNANT WOMEN IN POOR FAMILIES \\ (A Case Study In The Village Of Sri Kuncoro Pondok Kelapa District Central, Central Bengkulu)}

\author{
Eci Rentiani' ${ }^{1}$, Heri Sunaryanto ${ }^{2}$, Sri Handayani Hanum ${ }^{3}$ \\ hanum_bkl@yahoo.com \\ 123. Fakultas Ilmu Sosial dan Ilmu Politik, Universitas Bengkulu
}

\begin{abstract}
Abstrak
Penelitian ini bertujuan untuk mengetahui dan mendeskripsikan faktor-faktor buruknya gizi ibu hamil pada keluarga miskin. Penelitian didekati secara kualitatif deskriptif. Subyek penelitian adalah ibu hamil dari keluarga miskin. Ibu hamil ini hamil pada kehamilan ketiga. Informan ditentukan berdasarkan purposive sampling. Teknik observasi dan wawancara menjadi alat utama dalam menjaring data. Analisis data dimulai dari mereduksi data, penyajian data, dan penarikan kesimpulan. Penelitian menghasilkan informasi bahwa faktor-faktor penyebab buruknya gizi ibu hamil pada keluarga miskin yaitu: (1) Ibu hamil menganggap bahwa kehamilan bukan merupakan peristiwa khusus yang memerlukan perhatian ekstra melainkan sebagai hal yang biasa sehingga pemenuhan gizipun tidak berbeda saat hamil dan sebelum hamil. Adapun variasi makanan yang mereka konsumsi hanya memenuhi kebutuhan karbohidrat dan sayuran saja (2) Pola makan ibu hamil tidak teratur, mereka makan sehari hanya satu kali terkadang dua kali sehari (3) Pengolahan makanan seringkali tidak mempertimbangkan proses yang benar dimana persoalan nilai gizi kurang diperhatikan (4) Ibu hamil diberi tablet penambah darah oleh bidan sejak kehamilan lima bulan tetapi mereka kurang taat dalam mengkonsumsi tablet penambah darah dengan alasan tidak menyukai rasa dan bau dari tablet penambah darah tersebut (5) Ibu hamil tidak rutin melakukan pemeriksaan kehamilan karena menganggap jika sedang hamil trisemester pertama tidak perlu memeriksakan kandungan secara rutin kecuali kehamilan sudah memasuki trisemester 3 (6) Dukungan suami dalam hal pemenuhan gizi untuk istrinya ini cenderung kurang, ditunjukkan dengan besarnya belanja rokok setiap bulannya yang tidak berkurang, sehingga besarnya uang rokok setiap bulannya membuat kebutuhan akan panganlah yang ditekan.
\end{abstract}

Kata Kunci: Ibu hamil, Pemenuhan Gizi dan Miskin 


\begin{abstract}
This research aims to know and describe the factors of poor nutrition of pregnant women in poor families. Qualitative descriptive studies were approached. The subject of research is the pregnant women from poor families. This pregnant woman is pregnant on the third pregnancy. The informant is determined on the basis of purposive sampling. Observation and interview techniques became the main tool in the capture data. Data analysis starts from the reduction of the data, the presentation of data, and the withdrawal of the conclusion. The research produces information that the factors the causes of bad nutrition of pregnant women in poor families are: (1) pregnant women assume that pregnancy is not a special event that requires extra attention but as usual so the fulfillment of the gizipun is no different when pregnant and before getting pregnant. As for the variety of food they consume only meets the needs of carbohydrates and vegetables only. (2) diet of pregnant women is not organice, they eat only once a day, sometimes twice a day. (3) food processing often do not consider the process in which the question of less nutritional value. (4) pregnant women are given blood Enhancer tablets by midwives since the pregnancy five months but they are less devout in consuming the blood Enhancer tablets with reasons not to like the taste and smell of the blood Enhancer tablets. (5) pregnant women are not routinely pre-screen pregnancy considered if pregnant trisemester first need not be checked routinely content unless the pregnancy is already entering trisemester 3. (6) the husband's Support in terms of nutritional fulfillment of these tend to be less for his wife, indicated by the magnitude of the spending that not every month smoking decreases, so the magnitude of money smoking every month make the need for food is suppressed.
\end{abstract}

Keywords: Pregnant Women, Poor Nutrition and Fulfillment

\title{
PENDAHULUAN
}

Kemiskinan merupakan suatu kondisi serba kekurangan yang dialami seseorang sehingga tidak mampu memenuhi kebutuhan minimal hidupnya. Standar minimal kebutuhan hidup berbeda-beda antara satu daerah dengan daerah lainnya, karena batas kemiskinan suatu daerah itu sangat dipengaruhi oleh kebiasaan/adat, fasilitas transportasi dan distribusi pendapatan serta letak geografis suatu daerah. Kebutuhan minimal tersebut meliputi kebutuhan untuk makan terutama energi kalori, sehingga memungkinkan untuk memenuhi kebutuhan hidupnya (Santoso dan Indrawati, 2000: 4).

Tidak hanya kemiskinan saja yang menjadi persoalan masyarakat luas sekarang ini, kesehatan juga merupakan persoalan yang sangat penting untuk diperhatikan. Kesehatan yang menjadi sorotan sekarang ini adalah pada kesehatan ibu hamil. Tingginya jumlah angka kematian ibu (AKI) menjadi perhatian Dinas Kesehatan. Jumlah kematian ibu di Indonesia saat ini berdasarkan hasil Survei Demografi dan Kesehatan Indonesia (SDKI) tahun 2007 AKI telah mencapai 228 per 100.000 kelahiran hidup. Pada tahun 2012 Hasil SDKI menunjukkan bahwa AKI di Indonesia 
sebesar 359 per 100.000 kelahiran hidup jadi AKI pada tahun 2012 mengalami peningkatan dibandingkan dengan AKI tahun 2007. Bukan hanya AKI yang tinggi di Indonesia tetapi angka kematian bayi (AKB) juga tergolong masih tinggi di Indonesia. Angka kematian bayi di Indonesia tahun 2011 sebesar 24,8 kematian per 1000 kelahiran hidup, tahun 2012 meningkat sebesar 34 per 1000 kelahiran hidup (Kemenkes RI, 2012: 78).

Salah satu faktor penyumbang AKB adalah bayi berat lahir rendah (BBLR), berat badan bayi kurang dari 2500 gram dianggap berat bayi rendah. Jumlah bayi berat lahir rendah (BBLR) di Indonesia masih cukup tinggi. DataWHO mencatat Indonesia berada diperingkat sembilan di dunia dengan persentase BBLR lebih dari 15,5\% dari kelahiran bayi setiap tahunnya. Tingginya angka kelahiran BBLR di Indonesia salah satunya dikarenakan kurangnya pemenuhan gizi ibu hamil dan kurangnya pengetahuan ibu hamil terhadap konsumsi gizi selama mengandung yang bisa berdampak pada kesehatan kandungan dan bayi (Kemenkes RI, 2012: 63).

Rendahnya kesadaran masyarakat tentang kesehatan ibu hamil juga menjadi faktor penentu angka BBLR, meskipun masih banyak faktor yang harus diperhatikan untuk menangani masalah ini. Persoalan ini terjadi lantaran ada indikasi yang lazim muncul yakni seperti keracunan kehamilan yang disertai kejang-kejang dan infeksi. Namun, masih ada faktor lain yang cukup penting, yaitu masalah latar belakang pendidikan, kondisi sosial ekonomi keluarga, dan konsumsi gizi selama periode kehamilan serta lingkungan masyarakat juga ikut berpengaruh. Kaum laki-laki juga dituntut harus berupaya ikut aktif dalam segala permasalahan bidang reproduksi secara lebih bertanggung jawab. Selain masalah medis, tingginya angka BBLR juga karena masalah nilai budaya, perekonomian serta rendahnya perhatian laki-laki terhadap ibu hamil dan melahirkan. Pandangan yang menganggap kehamilan adalah peristiwa alamiah perlu diubah secara sosiokultur agar perempuan dapat perhatian dari masyarakat.

Desa Sri Kuncoro Kabupaten Bengkulu Tengah Kecamatan Pondok Kelapa pada tahun 2016 memiliki ibu hamil yang berjumlah 43 orang (sumber data arsip puskesmas pembantu dan bidan desa Sri Kuncoro) yang di antaranya terdapat 1 orang ibu hamil dari keluarga miskin dengan kehamilan ke-3 yang perlu diperhatikan asupan gizinya. Informan ibu hamil dalam penelitian ini merupakan keluarga yang peneliti 
kenal dan telah menjalin hubungan pertemanan sebelumnya, selain itu kedua ibu hamil ini semuanya dari keluarga miskin, jika dilihat dari pendapatan keluarga yang sebulannya kurang dari Rp. 750.000,- yang menurut Badan Pusat Statistik (BPS) Indonesia keluarga dianggap miskin jika pendapatannya kurang dari Rp.750.000,perbulannya. Penelitian ini mengenai buruknya gizi ibu hamil pada keluarga miskin. Penelitian difokuskan pada ibu hamil yang kurang memenuhi asupan gizi saat hamil dan ibu hamil yang memiliki suami serta sudah mempunyai anak dan dari keluarga miskin.

Fokus masalah dalam penelitian ini yaitu melihat penyebab gizi buruk ibu hamil pada keluarga miskin di Desa Sri Kuncoro Kecamatan Pondok Kelapa Kabupaten Bengkulu Tengah. Tujuan dari penelitian ini adalah untuk mendeskripsikan faktorfaktor penyebab buruknya gizi ibu hamil pada keluarga miskin di Desa Sri Kuncoro selama periode kehamilannya. Teori yang digunakan sebagai pandun menganalisis adalah teori aksi dalam Paradigma Definisi Sosial. Teori ini menekankan bahwa tindakan manusia manusia hanya dibatasi oleh kondisi yang tak dapat diubah dengan sendirinya. Di mana ibu hamil dalam melakukan tindakan memenuhi asupan gizinya dibatasi oleh kurangnya pengetahuan tentang asupan gizi saat hamil, akan mengalami kekurangan gizi karena ketidaktahuannya. Dimana pengetahuannya tentang gizi saat hamil yang dimiliki ibu hamil hanya sebatas tahu saja tanpa memahami dan mengaplikasikannya.

\section{METODE PENELITIAN}

Penelitian ini menggunakan metode penelitian deskriptif kualitatif dan dilakukan di Kabupaten Bengkulu Tengah, Kecamatan Pondok Kelapa, Desa Sri Kuncoro. Daerah ini dilihat peneliti mewakili untuk dijadikan lokasi penelitian karena adanya keluarga ibu hamil dari keluarga miskin yang kurang memenuhi asupan gizinya saat hamil. Metode pengumpulan data yang digunakan dalam penelitian ini yakni dengan menggunakan metode observasi, wawancara, dan dokumentasi. Penentuan informan dalam penelitian ini dilakukan dengan menggunakan teknik Purpossive Sampling. Pada penelitian ini, informan yang menjadi objek penelitian adalah ibu hamil dari keluarga miskin. Teknik analisis data yang digunakan yakni reduksi data, penyajian data, serta penarikan kesimpulan. 


\section{PEMBAHASAN}

Ibu hamil menganggap bahwa kehamilan bukan merupakan peristiwa khusus yang memerlukan perhatian ekstra melainkan sebagai hal yang biasa sehingga pemenuhan gizipun tidak berbeda saat hamil dan sebelum hamil. Adapun variasi makanan yang mereka konsumsi hanya memenuhi kebutuhan karbohidrat dan sayuran saja. Selain itu pola makan ibu hamil tidak teratur, ibu hamil makan sehari hanya satu kali terkadang dua kali sehari, ibu hamil makan sesuai dengan selera kapan mau makan saja sehingga tidak menerapkan pola makan sehat. Adapun pengolahan makanan yang dilakukan ibu hamil seringkali tidak mempertimbangkan proses yang benar dimana persoalan nilai gizi kurang diperhatikan.

Untuk tablet penambah darah ibu hamil diberikan oleh bidan sejak kehamilan lima bulan tetapi ibu hamil kurang taat dalam mengkonsumsi tablet penambah darah dengan alasan tidak menyukai rasa dan bau dari tablet penambah darah tersebut. Bukan hanya itu ibu hamil juga tidak rutin dalam melakukan pemeriksaan kehamilan karena menganggap jika sedang hamil trisemester pertama tidak perlu memeriksakan kandungan secara rutin kecuali kehamilan sudah memasuki trisemester 3. Sehingga diperlukan dukungan suami dalam hal pemenuhan gizi untuk istrinya. Namun dukungan suami ini cenderung kurang, ditunjukkan dengan besarnya belanja rokok setiap bulannya yang tidak berkurang, sehingga besarnya uang rokok setiap bulannya membuat kebutuhan akan panganlah yang ditekan.

Kelangsungan tindakan manusia hanya dibatasi oleh kondisi yang tak dapat diubah dengan sendirinya. Tindakan ibu hamil dalam memenuhi asupan gizinya dibatasi oleh kondisi yang tak dapat diubah dengan sendirinya. Sehingga kondisi rendahnya pendapatan keluarga dan kurangnya pengetahuan mengenai asupan gizi saat hamil, membatasi ibu hamil dalam memenuhi asupan gizinya. Hal ini menyebabkan ibu hamil tidak mengalami pertambahan berat badan pada usia kehamilan trisemester pertama dan mengalami penurunan berat badan pada usia kehamilan yang keenam bulan selain itu ibu hamil juga mengalami tekanan darah rendah (anemia) pada usia kehamilannya yang kelima dan keenam bulan. 
69 I Eci Rentiani, Heri Sunaryanto, Sri Handayani Hanum

Buruknya Gizi Ibu Hamil Pada Keluarga Miskin

\section{KESIMPULAN}

Berdasarkan hasil penelitian, dapat disimpulkan bahwa, (1) Ibu hamil menganggap bahwa kehamilan bukan merupakan peristiwa khusus yang memerlukan perhatian ekstra melainkan sebagai hal yang biasa sehingga pemenuhan gizipun tidak berbeda saat hamil dan sebelum hamil. Adapun variasi makanan yang mereka konsumsi hanya memenuhi kebutuhan karbohidrat dan sayuran saja. (2) Pola makan ibu hamil tidak teratur, mereka makan sehari hanya satu kali terkadang dua kali sehari. (3) Pengolahan makanan seringkali tidak mempertimbangkan proses yang benar di mana persoalan nilai gizi kurang diperhatikan. (4) Ibu hamil diberi tablet penambah darah oleh bidan sejak kehamilan lima bulan tetapi mereka kurang taat dalam mengkonsumsi tablet penambah darah dengan alasan tidak menyukai rasa dan bau dari tablet penambah darah tersebut. (5) Ibu hamil tidak rutin melakukan pemeriksaan kehamilan karena menganggap jika sedang hamil trisemester pertama tidak perlu memeriksakan kandungan secara

Saran yang diberikan berdasarkan hasil penelitian yaitu (1) Sebaiknya suami dari informan ibu hamil ini mengurangi konsumsi rokok atau berhenti merokok karena pendapatan keluarga yang rendah membuat kebutuhan akan gizi ditekan karena besarnya uang setiap bulannya untuk membeli rokok. (2) Ibu hamil sebaiknya lebih memiliki pengetahuan tentang asupan gizi yang baik seperti makanan yang bervariasi, seimbang dan sehat untuk dikonsumsi saat hamil supaya bisa memenuhi kebutuhan gizi dengan baik agar kesehatan ibu dan janin terjaga selain itu asupan gizi yang dikonsumsi ibu juga berpengaruh pada tumbuh kembang janin. Jika ibu hamil sudah mempunyai pengetahuan mengenai asupan gizi yang baik saat hamil, maka diharapkan ibu hamil dapat memenuhi asupan gizinya dengan baik. (3) Sebagai seorang ibu hendaknya, lebih memperhatikan kandungannya dengan memenuhi gizinya dan memiliki pola makan yang teratur, serta rutin dalam meminum obat penambah darah untuk mengurangi resiko ibu kekurangan darah atau ibu mengalami anemia. (4) Sebagai suami yang baik, berikan perhatian pada istri yang sedang hamil. Berbagai bentuk perhatian dapat diberikan pada istri. Jangan biarkan istri merawat kehamilannya sendiri. Kehamilan istri juga merupakan tanggung jawab suami yang ikut serta merawat kehamilan dan berusaha juga untuk memenuhi kebutuhan gizi istri. (5) Lakukan perawatan kehamilan terutama pemenuhan gizi dan pemeriksaan kehamilan dengan rutin setiap bulannya. 


\section{DAFTAR PUSTAKA}

Almatsier, S. 2005. Manfaat Makanan Sehat Edisi Baru. Jakarta: Gramedia Pustaka Utama.

Arif, Fauzi. 2009. Buku Panduan Perawatan Kehamilan. Yogyakarta: Cakrawala.

Christianingrum. 2005. Kebutuhan Makan Ibu Hamil. Jakarta: Fakultas Kedokteran Universitas Indonesia.

Dewi. 2008. Perencanaan Keuangan Menyambut Kehamilan dan Persalinan. 15 Maret, 2016 (http://@Dewi Perencanaan Keuangan Menyambut Kehamilan dan Persalinan.pdf).

Hamonangan Ritonga. 2010. Mengapa Kemiskinan di Indonesia Menjadi Masalah Berkelanjutan.13 Juni 2016 (http://www.wordpress.com/cetak/0402/10/ekonomi/847162.htm).

Kementrian Kesehatan RI. 2012. Status Kesehatan Masyarakat. http://depkes.go.id (diakses juni M. Torsina. 2010. PemeriksaanKehamilan: Isu dan Tip. Jakarta.PT Buana Ilmu Populer. 